\title{
Mechanical Properties and Corrosion Resistance of SA508-4 Low Carbon Alloy Steel

\author{
Dahai XIA, ${ }^{a, b}, *$ Chao ZHOU, ${ }^{a}$ Yuhuan LIU, ${ }^{a}$ Jihui WANG, ${ }^{a}, *$ \\ Congwei FU, ${ }^{a}$ Ke WANG, ${ }^{a}$ and Ming LI ${ }^{b}$
}

\author{
a School of Materials Science and Engineering, Tianjin University, Tianjin 300072, P. R. China \\ b Department of Chemical and Materials Engineering, University of Alberta, Edmonton, Alberta, Canada T6G 2V4 \\ *Corresponding author: dahai@ualberta.ca, jhwang@tju.edu.cn
}

\begin{abstract}
The mechanical properties and corrosion resistance of SA508-4Ni-Cr-Mo low carbon alloy steel are elucidated using tensile testing, Charpy impact testing, fracture surface analysis and in-situ electrochemical noise (EN) technique. The metallographic structures are characterized by metallographic microscope combining with transmission electron microscope (TEM), and the fracture morphology is characterized by scanning electron microscope (SEM). The intercritical heat treatment (IHT) is introduced to heat the SA508-4 steel. The experimental observations reveal that the metallographic structure of SA508-4 steel is fine and uniform after different heat treatment, with martensite and lower bainite structures. The strength and toughness of SA508-4Ni-Cr-Mo are confirmed higher than that of SA508-3Mn-Ni-Mo steel used for reactor pressure vessels (RPV) at present. The IHT decreases the yield strength and toughness. EN results show that the noise resistance of SA508-4 steel decreased with the elevated temperature from 27 to $250^{\circ} \mathrm{C}$, illustrating the passivity degradation of SA508-4 induced by the elevated temperature.
\end{abstract}

(c) The Electrochemical Society of Japan, All rights reserved.

Keywords : SA508-4Ni-Cr-Mo Steel, Mechanical Performance, Electrochemical Noise, Corrosion Resistance

\section{Introduction}

The reactor pressure vessel (RPV) is the key component in determining the lifetime of nuclear power plants because it is subject to significant aging phenomenon of irradiation embrittlement and there is no practical method for replacing that component. For materials used for the RPV, sufficient strength and toughness are required to prevent failure against the operating conditions and the aging degradation of materials. The RPVs of Pressurized Water Reactors (PWRs) have mostly been made of SA508 Grade 3 (SA508-3) low alloy steels which have revealed moderate mechanical properties and a moderate radiation resistance for a 40 or 60 year operation. The SA508 Grade 4, low alloy steels with a higher strength and toughness can help to increase the safety and economy of the advanced PWR systems which will be launched in the near future. ${ }^{1}$ SA508 Grade 4 Ni-Cr-Mo (SA508-4) low alloy steel provides a way to increase both the strength and toughness by a chemistry modification, especially by increasing the $\mathrm{Ni}$ and $\mathrm{Cr}$ contents, which can reduce the transformation rate from austenite to ferrite and carbides, then make the continuous cooling transformation (CCT) curve move towards right, further lower the critical cooling rate for quenching. However, this higher strength steel has a deficiency due to a lack of operating data for nuclear power plants. For examples, the strength and toughness after heat treatment are still not clear. Since the benefits from a higher strength and toughness seem to be considerable, it is recommended that more detailed and intensive experimental programs are carried out to fully characterize the SA508-4 steels from the viewpoint of the corrosion resistance, the effects of heat treatment, and the long-term aging behaviors. Researches have been conducted to increase the strength and toughness of low alloy RPV steels by an optimization of the heat treatment. K. H. Lee et al. ${ }^{2}$ investigated the relationship between fracture toughness behavior and phase fraction of SA5084 steel, the results showed that the yield strength and the impact toughness at room temperature are improved by the increased tempered martensite fraction. Intercritical heat treatment (IHT) is a new heat treatment that can enhance the strength and toughness of SA508-3Mn-Ni-Mo steel, because the IHT can lead to more martensite whose fraction is $20-60 \% .^{3}$ So, in this study, the IHT is adopted for SA508-4 Ni-Cr-Mo steel in order to improve the mechanical performance.

The service environment of nuclear RPV steel is severe, because it is contacted with high temperature, high pressure and corrosive solution with long time. The environment can make the materials degrade severely. ${ }^{4,5}$ Therefore, it is important to study the corrosion resistance of SA508-4 steel in high pressurized water condition. It is known that there are various electrochemical methods to study the corrosion phenomena, including electrochemical impedance spectroscopy (EIS), ${ }^{6-9}$ electrochemical noise (EN), ${ }^{10-12}$ polarization curve $^{13,14}$ and so on. EN appears as a choice for its study, with a number of attractive features for corrosion research and engineering. EN measurement has been proved to be one of the most promising methods for detecting corrosion types, such as passivation, ${ }^{15}$ uniform corrosion, ${ }^{15}$ local corrosion, ${ }^{14,16}$ and stress corrosion cracking. ${ }^{17-19} \mathrm{EN}$ is a general term given to fluctuations in the potential and current generated spontaneously by corrosion processes. EN occurs naturally in the electrolyte/electrode interface due to the random ion movements and also originates from the occurrence of cooperative phenomena such as nucleation of pits etc. More deeply, EN is associated with all degrees of freedom of the system. ${ }^{20}$ It indicates a change in the thermodynamic and kinetic states of the interface and it is the only electrochemical technique that does not disturb the system. ${ }^{21}$ The corrosion and corrosion-related processes and mechanisms identified as sources of EN include, among others, the nucleation and propagation of stress corrosion cracks; hydrogen bubble nucleation, growth, and detachment; passive film formation and growth; nucleation, growth, and propagation of pits; abrasion; resistance change and diffusion in 
Table 1. Chemical compositions of the specimens (wt\%).

\begin{tabular}{ccccccccccccc}
\hline Material & $\mathrm{C}$ & $\mathrm{Cr}$ & $\mathrm{Ni}$ & $\mathrm{Mn}$ & $\mathrm{Mo}$ & $\mathrm{Si}$ & $\mathrm{P}$ & $\mathrm{S}$ & $\mathrm{Al}$ & $\mathrm{Cu}$ & $\mathrm{V}$ & $\mathrm{Fe}$ \\
\hline SA508-4 & 0.19 & 1.70 & 3.40 & 0.33 & 0.51 & 0.21 & 0.0050 & 0.0044 & 0.087 & 0.040 & 0.0071 & $\mathrm{Bal}$ \\
$\mathrm{SA508-3}$ & 0.18 & 0.16 & 0.70 & 1.44 & 0.50 & 0.21 & 0.0049 & 0.0034 & 0.064 & 0.042 & 0.0055 & Bal \\
\hline
\end{tabular}

Table 2. The heat treatment and the sample numbers.

\begin{tabular}{ccc}
\hline $\begin{array}{c}\text { Sample } \\
\text { number }\end{array}$ & Steel & Heat treatment \\
\hline 3a & SA508-3 & $890^{\circ} \mathrm{C} \times 30$ min quenching (water) $\rightarrow 650^{\circ} \mathrm{C} \times 60$ min tempering \\
4a & SA508-4 & $880^{\circ} \mathrm{C} \times 30$ min quenching (air) $\rightarrow 660^{\circ} \mathrm{C} \times 60$ min tempering \\
$4 \mathrm{~b}$ & SA508-4 & $880^{\circ} \mathrm{C} \times 30$ min quenching (air) $\rightarrow 720^{\circ} \mathrm{C} \times 60$ min annealing \\
4c & SA508-4 & $880^{\circ} \mathrm{C} \times 30$ min quenching (air) $\rightarrow 720^{\circ} \mathrm{C} \times 60$ min annealing $\rightarrow 630^{\circ} \mathrm{C} \times 40$ min tempering \\
$4 \mathrm{~d}$ & SA508-4 & $880^{\circ} \mathrm{C} \times 30$ min quenching (water) $\rightarrow 660^{\circ} \mathrm{C} \times 60$ min tempering \\
\hline
\end{tabular}

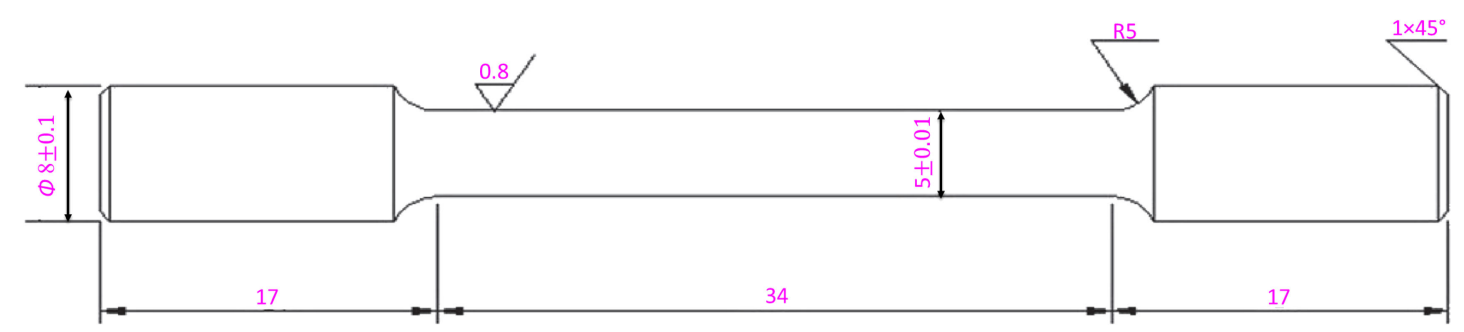

Figure 1. (Color online) The geometry of specimens used in the tensile experiment (Dimensions are in $\mathrm{mm}$ ).

solution; high-temperature corrosion; and microbial corrosion and uniform corrosion.

This work has been performed with the intention to study the mechanical properties of SA508-4 steel by the modification of heat treatment process to change the microstructure, and to investigate the corrosion resistance of the steel in high temperature and high pressurized water.

\section{Experimental}

\subsection{Materials and heat treatment}

The chemical compositions of SA508-4 Ni-Cr-Mo steel and SA508-3 Mn-Ni-Mo steel are shown in Table 1. The heat treatment and the sample numbers are listed in Table 2. Heat treatment $3 \mathrm{a}$ is the treatment that is adopted in industrial application at present. Heat treatment $4 \mathrm{a}$ is the treatment that has been proved be an effective way in the laboratory, ${ }^{22}$ making the metal have an excellent performance both in strength and toughness. It consists of quenching in the air after austenitizing and then tempering at high temperature. As seen in Table 2, IHT is introduced to $4 \mathrm{~b}, 4 \mathrm{c}$. Compared with $4 \mathrm{a}$, $4 \mathrm{~d}$ consists of quenching in the water after austenitizing and then tempering at high temperature. The difference is that quenching in the water - $\mathrm{a}$ faster cooling rate. After heat treatment, the specimen $(10 \mathrm{~mm} \times 10 \mathrm{~mm} \times 10 \mathrm{~mm})$ were ground to 2000 grid paper and polished with $0.25 \mu \mathrm{m}$ diamond suspension. And then, the specimens were degreased with ethanol and etched with $4 \%$ nital solution. In the preparation of foils for TEM observation, the specimens were ground mechanically and then polished in sulphuric acid + methanol $(1: 4)$ at $-20^{\circ} \mathrm{C}$ by a twin jet polisher. The microstructure was examined by optical microscope (OM) and transmission electron microscopy (TEM) (Tecnai G2 F20; Philips, Netherlands).

\subsection{Tensile test}

The dimensions of the specimens used for tensile testing are shown in Fig. 1. The strain rate was $2 \mathrm{~mm} / \mathrm{min}$. The tensile test was condued at room temperature (about $23^{\circ} \mathrm{C}$ ).

In engineering, stress and strain are calculated as follows:

$$
\sigma=\frac{P}{A}
$$

where $P$ is load and $A$ is the sectional area of the specimen.

$$
\varepsilon=\frac{L-L_{0}}{L}
$$

where $L_{0}$ is the original gauge length of the specimen and $L$ is the length of the specimen after deformation. In this study, $L_{0}$ is $25 \mathrm{~mm}$.

\subsection{Impact testing}

The Charpy impact test was performed according to standard test methods for notch bar impact testing of metallic materials (ASTM E 23-07a) at room temperature (about $23^{\circ} \mathrm{C}$ ). The total length of the specimen was $55 \mathrm{~mm}$ and the square cross-section area was $10 \mathrm{~mm} \times 10 \mathrm{~mm}$. Specimen had a V-shaped notch with a flank angle of $45^{\circ}$ and depth of $2 \mathrm{~mm}$. The tip radius of notch was $0.25 \mathrm{~mm}$. The radius of striking edge was $8 \mathrm{~mm}$. Before test, specimen was positioned upon two anvils with a span of $40 \mathrm{~mm}$. After impact fracture, the absorbed impact energy was obtained, and the fracture surfaces were observed via scanning electron microscope (SEM) (FE-SEM S4800; Hitachi, Japan).

\subsection{Electrochemical measurement}

There are two major challenges in developing the electrode suitable for use in high temperature and high pressurized environment. The first one is the sealing problem. The electrodes should be exposed to high temperature solution in which these electrodes are supposed to work, but all other parts of the electrodes should not be in contact with the solution. Furthermore, the sealing system should be such so as to avoid crevice corrosion. Secondly, there exists the problem of contamination of the working solution, due to the 


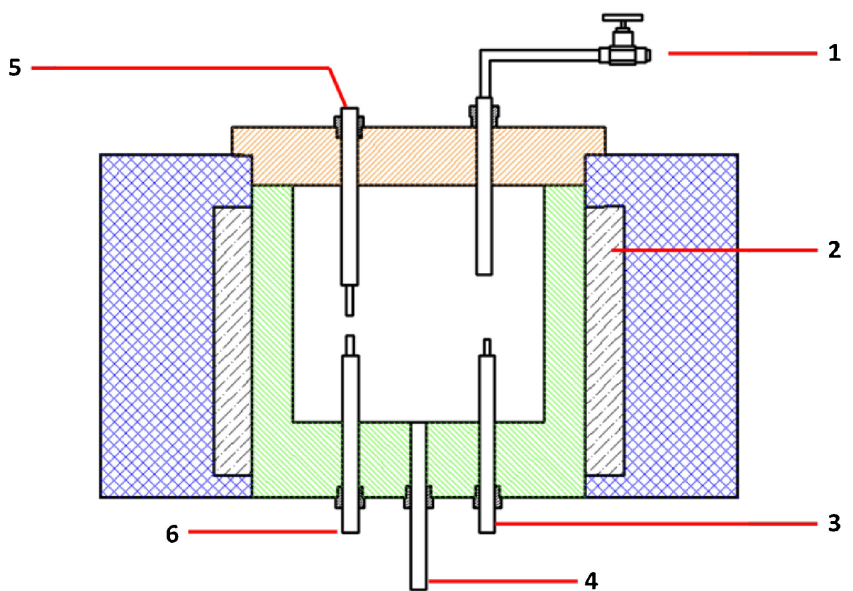

Figure 2. (Color online) Schematic illustration of the high temperature and high pressure reactor. 1- $\mathrm{N}_{2}$ inlet; 2- heater; 3- counter electrode; 4- liquid outlet; 5- working electrode; 6- reference electrode.

dissolution of the metallic components of the experimental system under the high temperature water conditions. In the worst case, the composition could change dramatically during data acquisition and a steady electrochemical state may never be achieved. We have employed a number of techniques to solve these problems in the study.

The EN measurement here consisted of three electrodes. As shown in Fig. 2, two of the electrodes, working electrode and counter electrode, were type SA508-4 steel bars with a diameter of $5 \mathrm{~mm}$ that made from the same roll of virgin material. The areas of both the two electrodes were $5.00 \mathrm{~cm}^{2}$. The third electrode was a platinum wire with a diameter of $0.50 \mathrm{~mm}$. All three electrodes were inserted into a ceramic tube, respectively. The extra space of the tube was filled with high temperature zirconia $\left(\mathrm{ZrO}_{2}\right)$ cement which was also used as the sealant for the ends of the tube. The working electrode and counter electrode were abraded with silicon carbide paper from $400 \#$ to $5000 \#$, washed with acetone and deionized water, and then dried. In order to observe the surface morphology of the steel at different temperature, another type of the specimens $(10 \mathrm{~mm} \times 10 \mathrm{~mm} \times 2 \mathrm{~mm})$ were placed in the reactor.

The experiment solution was deaerated $1500 \mathrm{ppm} \mathrm{H}_{3} \mathrm{BO}_{3}+$ $2.3 \mathrm{ppm} \mathrm{LiOH} \cdot \mathrm{H}_{2} \mathrm{O}+50 \mathrm{ppb} \mathrm{Zn}\left(\mathrm{CH}_{3} \mathrm{COO}\right)_{2} \cdot \mathrm{H}_{2} \mathrm{O}$. The solution was heated up from 27 to $250^{\circ} \mathrm{C}$, and the $\mathrm{EN}$ was measured simultaneously between one of the working electrodes and the reference electrode through a zero resistance ammeter (ZRA) mode by using a VersaSTAT 4 electrochemical workstation (Princeton Applied research, USA) and VersaStudio control software. The sampling time corresponded to each temperature was $7680 \mathrm{~s}$, which can be divided into fifteen $512 \mathrm{~s}$, the noise resistance for each $512 \mathrm{~s}$ was calculated. The sampling frequency was $2 \mathrm{~Hz}$. The direct current (dc) component was first removed from original electrochemical potential noise (EPN) data by a 5-order polynomial fitting. At least 3-4 specimens of each type were evaluated in each experiment in order to guarantee the reproducibility of the noise data. This paper shows the result from one of the samples.

\section{Results and Discussions}

\subsection{Microstructure characterization}

Figure 3 shows the typical microstructures of SA508-4 Ni-CrMo steel after different heat treatments that listed in Table 2. The microstructure after quenching and tempering is lath martensite and a small number of needle-type bainite; coarse carbides are rarely found in the refined microstructure, as shown in Fig. 3(a). The structure of 4a is very fine and homogeneous. In Figs. 3(b) and 3(c),
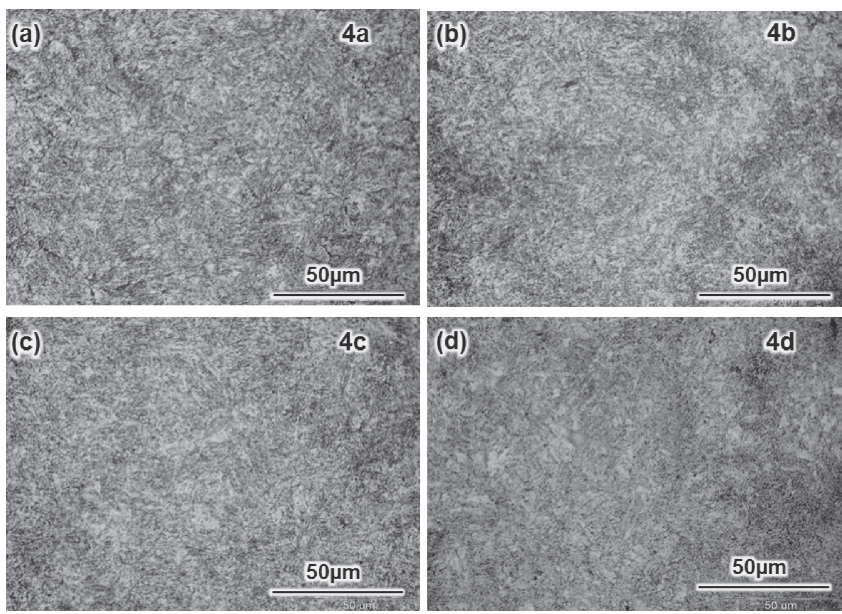

Figure 3. Metallography of SA508-4 Ni-Cr-Mo steel after different heat treatments: (a) 4a; (b) 4b; (c) 4c; (d) $4 d$.

typical martensite is observed in the microstructure of SA508-4 after quenching and IHT. The different is that the quantity of lath martensite becomes more, because martensite is formed during cooling from the austenite phase which is formed during the intercritical annealing. During the heating and annealing at an intercritical temperature, the carbides dissolve as carbon and metal atoms, the austenite phase forms at grain boundaries and lath boundaries where the carbon content increases rapidly. In the subsequent cooling process, the austenite phase transforms to martensite because the enrichment of the alloying elements is enough to have a sufficient hardenability for the martensite transformation under a given cooling rate. The martensite generated in the previous quenching process is untransformed during IHT and remains unchanged during the subsequent cooling process. In Fig. 3(d), martensite can also be found after quenching in water and tempering, with a high cooling rate. In summary, it is found that sufficient lath martensite can be transformed after quenching both in the air and in water. Considered the industrial applicability and economy, the quenching in the air and tempering is better.

Since carbide cannot be distinguished from ferrite, and the submicroscopic structure cannot be seen clearly from the images obtained from optical microscope, TEM is used to observe the finestructure of ferrite and the shape and distribution of the carbide. The TEM images of SA508-4 steels after different heat treatment are presented in Fig. 4. In general, the "white" region is ferrite, and the black granular or lath precipitates are carbides. The fine precipitates in the SA508-4 alloy are generally Cr-type carbides identified to be $\mathrm{M}_{7} \mathrm{C}_{3}$ or $\mathrm{M}_{23} \mathrm{C}_{6} \cdot{ }^{23}$ In Fig. 4(a), the black structures with high density dislocation are martensite which can be found more in Figs. 4(b) and 4(c); the density of dislocation become higher in Figs. 4(b) and 4(c). During the IHT and tempering process, most carbides with sphere type are formed at the interface between martensite or within the martensite where concentrate higher content of alloying elements. In Fig. 4(d), the quenching with high cooling rate (in water) is adopted, leading to the precipitation of some fine and dispersed carbides. In this situation, $\mathrm{C}$ and $\mathrm{Fe}$ atoms cannot completely diffuse for a long distance because of the high cooling rate, and the carbides cannot grow up, so this give rise to a very fine martensite structure.

Compared with SA508-4 steel, the typical microstructure features of the SA508-3 pressure vessel steels are presented in Fig. 5, a tempered bainite microstructure with coarse carbides distributed along the lath boundaries. Carbide particles with long rod shape are distributed in the regions between bainitic ferrite laths. This interlath region is formed in the later stage of bainite transformation, by 

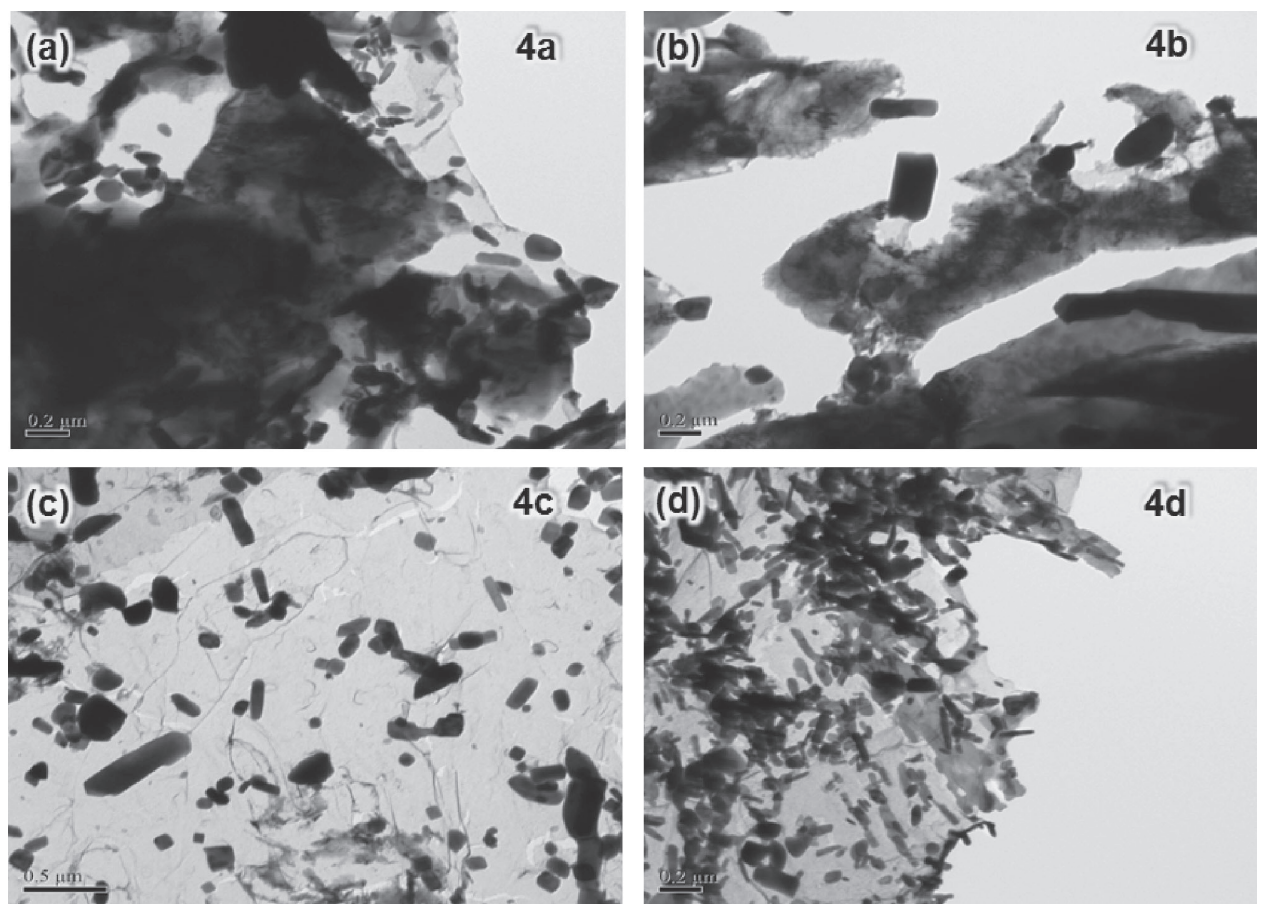

Figure 4. TEM images of SA508-4Ni-Cr-Mo steel after different heat treatments: (a) 4a; (b) 4b; (c) 4c; (d) 4d.

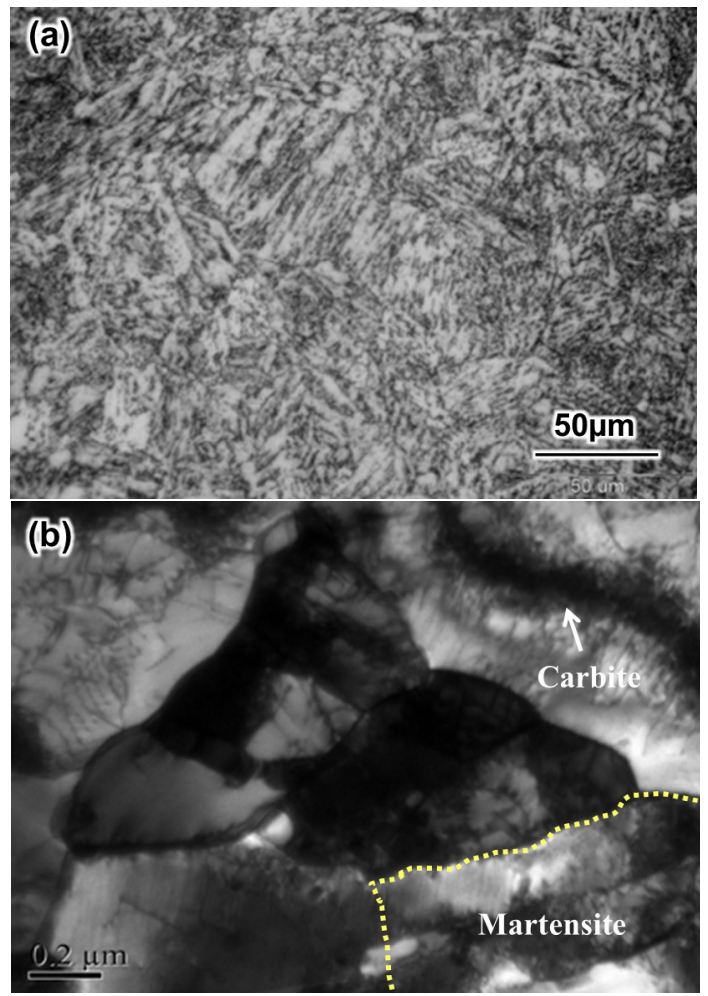

Figure 5. (Color online) Microstructure of SA508-3 Mn-Ni-Mo steel: (a) optical microscope image, (b) TEM image.

the enrichment of carbon from surrounding bainitic ferrite laths. Higher magnification TEM micrograph reveals that inter-lath region is an aggregate of long rod type and spherical type carbide particles. ${ }^{3}$ A small number of martensite structures are observed maybe due to the cooling rate is high enough.

\subsection{Mechanical properties}

SA508-4 steel has a different chemistry composition from SA508-3 steel, which will result to better mechanical properties in

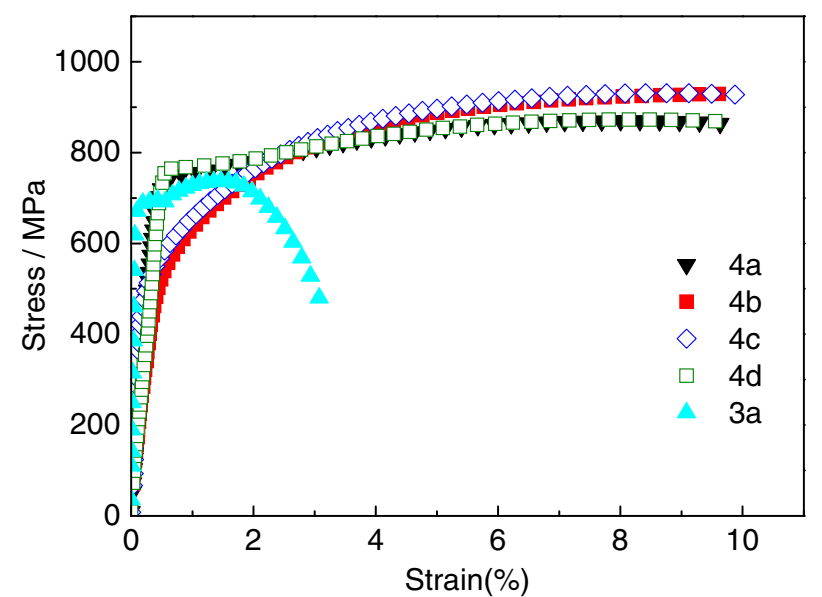

Figure 6. (Color online) Stress-strain curve of SA508-4 and SA508-3 steel.

both their strength and toughness. The main difference between Grade 4 and Grade 3 steel is that the alloy contents of $\mathrm{Ni}$ and $\mathrm{Cr}$ are increased while the Mn content is reduced. This steel is often called a Ni-Cr-Mo steel. The elevated Ni content can increase the hardenability and so the heat treatment of thick components can be easier. IHT is conducted on SA508-4, generating a more quantity of martensite and higher density dislocation.

The tensile property can be obtained by measuring the stressstrain curve. Subsequently, yield strength, tensile strength and the variation of stress as a function of strain can be obtained. Figure 6 is the stress-strain curve of SA508-4 together with SA508-3 steel. Table 3 summarizes the tensile experimental data from the stressstrain curve, where $R_{\mathrm{p} 0.2}$ is the yield strength which was determined by a $0.2 \%$ strain offset stress $(\varepsilon=0.2 \%) ; R_{\mathrm{m}}$ is the tensile strength; $A$ is the elongation after fracture, measured using a vernier caliper.

From Fig. 6, it can be found that the yield strength of $4 \mathrm{a}$ and $4 \mathrm{~d}$ is higher than that of SA508-3 steel, and the strain of SA508-4 steel caused by tension is also higher than that of SA508-3 steel, 

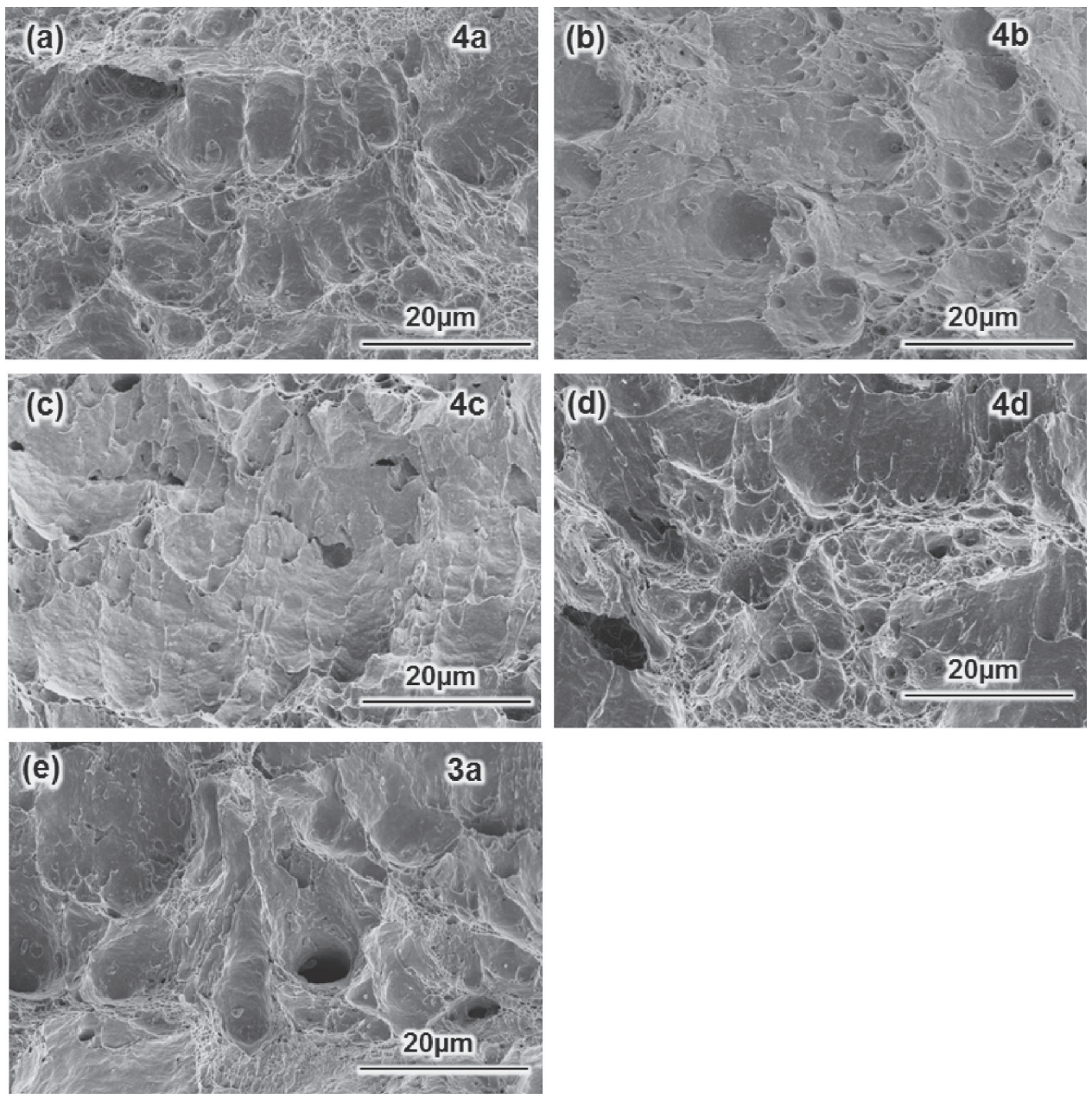

Figure 7. The fracture morphology of the SA508-3 and SA508-4 steels after the impact test: (a) 4a; (b) 4b; (c) 4c; (d) 4d; (e) 3a.

Table 3. Tensile experimental data of specimens after different heat treatment.

\begin{tabular}{cccc}
\hline Specimen & $R_{\mathrm{m}} / \mathrm{MPa}$ & $R_{\mathrm{p} 0.2} / \mathrm{MPa}$ & $A / \%$ \\
\hline 3a & 750 & 685 & 20.28 \\
$4 \mathrm{a}$ & 820 & 755 & 22.80 \\
$4 \mathrm{~b}$ & 845 & 600 & 22.26 \\
$4 \mathrm{c}$ & 845 & 610 & 22.76 \\
$4 \mathrm{~d}$ & 820 & 750 & 22.60 \\
\hline
\end{tabular}

indicating the deformation before fracture is substantial so the toughness is better. The area below the stress-strain curve can characterize the toughness of metal materials; a larger area means a higher toughness and fracture-resistance. It can be seen that those areas of SA508-4 are much larger than that of SA508-3 steel. Therefore, SA508-4 is more excellent than SA508-3 both in strength and toughness. The elongation after fracture of SA508-4 is $10 \%$ higher than that of SA508-3 (Table 3), which is attributed to the high quantity of lath martensite structure that existed in SA508-4 steel. The lath martensite structure gives a higher strength and toughness, thus a better integrated mechanical property. In addition, high content of $\mathrm{Ni}$ and $\mathrm{Cr}$ can enhance the hardenability and improve the impact toughness. Cr can affect the precipitation of carbide, leading to uniform and fine carbides that can improve both in the strength and toughness. According to the stress-strain curve of SA5008-4 steel specimens, the yield strength of $4 \mathrm{a}$ and $4 \mathrm{~d}$ are higher than $4 \mathrm{~b}$ and $4 \mathrm{c}$. The yield point doesn't appear in the stress-strain curve of $4 \mathrm{~b}$ and $4 \mathrm{c}$, and strain hardening appears, which can be attributed to the IHT process. In the IHT process, the residual austenite after quenching could transform to martensite again, making a higher content of martensite and higher density dislocation. If the dislocation with high density moves, the stress must be added to produce strain, so the yield point doesn't appeared. The strength of $4 \mathrm{a}$ and $4 \mathrm{~d}$ are nearly the same, which indicates that the martensite can transform suitably after quenching both in the air and water. After conventional heat treatment of quenching and tempering, the yield strength and tensile strength of SA508-4 steel is higher than that of SA508-3 steel, and the elongation after fracture increased substantially, this is attributed to the higher toughness.

After impact test, the fracture surfaces are observed via SEM. The morphology of the impact fracture surfaces are shown in Fig. 7. The dimple on the impact fracture surface can characterize the toughness: if the number of the dimple is more and the size of dimple is deeper and larger, the toughness is better. It is observed that the number of the dimple of SA508-4 is more than that of SA508-3, and the size is deeper. The size and the uniformity degree of the dimple are determined by the internal toughness of the materials, thus the fracture characteristics indicate the toughness of SA508-4 steel is higher than that of SA508-3. Figure 7 also shows the size of dimple on the fracture surface of $4 \mathrm{a}$ and $4 \mathrm{~d}$ is larger than $4 \mathrm{~b}$ and $4 \mathrm{c}$, which is attributed to the reduced toughness during the IHT process. The structure of $4 \mathrm{c}$ is obtained after tempering of $4 \mathrm{~b}$. Because tempering can eliminate a part of internal stress, a better toughness can be seen in the fracture surface in $4 \mathrm{c}$ than $4 \mathrm{~b}$, as shown in Figs. 7(b), 7(c). 
Table 4. Impact toughness results in room temperature.

\begin{tabular}{cc}
\hline Sample numbers & Impact absorbing energy $(J)$ \\
\hline $3 \mathrm{a}$ & 208 \\
$4 \mathrm{a}$ & 224 \\
$4 \mathrm{~b}$ & 118 \\
$4 \mathrm{c}$ & 180 \\
$4 \mathrm{~d}$ & 226 \\
\hline
\end{tabular}

Impact toughness is defined as the amount of energy that a material can absorb from a sudden, sharp blow before it breaks or fractures. The impact toughness of materials can be reflected by the absorbed energy in the charpy impact test. Since toughness is greatly affected by temperature, the charpy impact test is often carried out at different temperatures. The absorbed impact energy of different specimens at room temperature is summarized in Table 4 . The absorbed impact energy of $4 \mathrm{a}$ is $224 \mathrm{~J}$, higher than that of SA508-3 steel, $208 \mathrm{~J}$, which indicates that the impact toughness of $4 \mathrm{a}$ is better than that of $3 \mathrm{a}$. As mentioned above, the quantity of martensite in $4 \mathrm{~b}$ and $4 \mathrm{c}$ is more due to the IHT process, which lead to a decreased toughness. But tempering process after annealing could eliminate inner stress, therefore, toughness of $4 \mathrm{c}$ is higher than that of $4 \mathrm{~b}$, and the absorbed impact energy of $4 \mathrm{a}$ and $4 \mathrm{~d}$ are nearly the same. It also indicates that the cooling rate in the air is high enough to make SA508-4 steel contain a certain amount of lath martensite, which makes SA508-4 steel show a good comprehensive performance both in strength and toughness.

The above results show that the IHT process is probably not suitable for use in the heat treatment of SA508-4 steel, because IHT decreases both the toughness and the yield strength of the steel.

\subsection{Corrosion resistance in high temperature and high pressure water}

In situ electrochemical noise is conducted on SA508-4 steel in order to monitor the electrochemical signals during corrosion process. Figure 8 is the electrochemical potential (EPN) and electrochemical current noise $(\mathrm{ECN})$ data measured at the temperatures $\left(27,100,150,200,250^{\circ} \mathrm{C}\right)$, and the $\mathrm{EN}$ data for each temperature is collected for $7680 \mathrm{~s}$. It can be seen that both EPN and ECN exhibit features of "white noise" with very high repetition rates. The amplitudes of EPN are about $1 \mathrm{mV}$ and nearly unchanged during the whole corrosion process, as shown in Fig. 8(a). But the amplitudes of ECN increase from 25 to $60 \mu \mathrm{A}$, following with the temperature stepped from 27 to $250^{\circ} \mathrm{C}$ [Fig. 8(b)]. The increased amplitudes of ECN imply the corrosion degree of SA508-4 steel in high temperature solution become more serious, especially at $250^{\circ} \mathrm{C}$.

Figure 9 is the calculated standard deviation of EPN and ECN, and noise resistance $R_{\mathrm{n}}$. It can be seen that the standard deviation of EPN are nearly unchanged while the standard deviation of ECN become higher as the temperature elevated [Figs. 9(a), 9(b)]. Noise resistance was calculated as the ratio of standard deviations of the simultaneously measured potential and current noise signals: $R_{\mathrm{n}}=\sigma(V) / \sigma(I)$. From Fig. $9(\mathrm{c})$, it is obvious that $R_{\mathrm{n}}$ decrease with an increase of the temperature, indicating an increased corrosion rate of the metal. It is known that the corrosion resistance of a mental is related to its passive film, this indicates that the passive film degrade in the high temperature and high pressurized conditions, especially at $250^{\circ} \mathrm{C}$.

Figure 10 is the surface morphology of SA508-4 steel at different temperatures and pressures. At $27^{\circ} \mathrm{C}$, the surface is intact and no corrosion pits are observed [Fig. 10(a)]. When the temparature is elevated to $100^{\circ} \mathrm{C}$, some corrosion pits can be seen on the electrode surface, illustrating an higher corrosion rate [Fig. 10(b)]. As the (a)

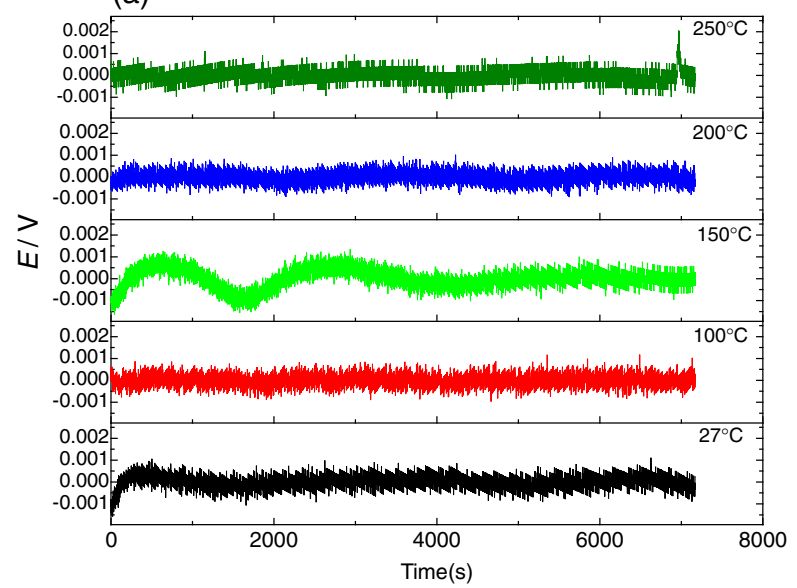

(b)

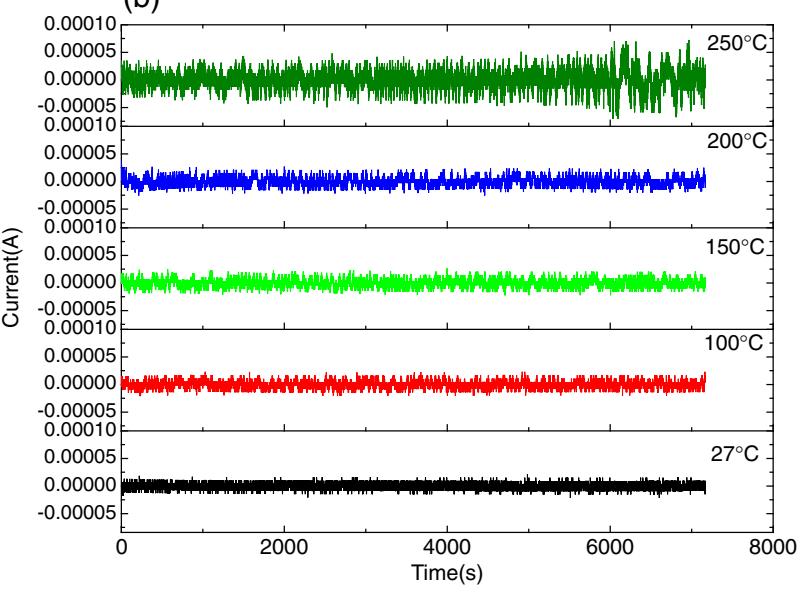

Figure 8. (Color online) Measured EN data with the elevated temperature and pressure: (a) EPN data; (b) ECN data.

temperature continues to elevate, more corrosion pits are seen on the surface [Figs. 10(c), 10(d)]. But the electrode suffers a more serious corrosion when the temperature is $250^{\circ} \mathrm{C}$, leading to many corrosion pits on the surface [Fig. 10(e)].

\section{Conclusions and Recommendations}

The mechanical properties and corrosion resistance of SA5084Ni-Cr-Mo low carbon alloy steel using tensile testing, charpy impact testing, fracture surface analysis and in-situ electrochemical noise (EN) techniques, and the results permit the following conclusions:

1. The experimental observations reveal that the metallographic structure of SA508-4 is fine and uniform after different heat treatments, with martensite and a small quantity of lower bainite structure.

2. The tensile strength and toughness of SA508-4Ni-Cr-Mo are confirmed higher than that SA508-3Mn-Ni-Mo steel used for RPV at present.

3. Intercritical heat treatment (IHT) is probably not suitable for use in SA508-4 steel, because IHT decreases both the toughness and the yield strength of the steel.

4. EN results show that noise resistance decreased with the temperature from 27 to $250^{\circ} \mathrm{C}$, illustrating the passivity degradation of SA508-4 induced by an increase of temperature.

The electrochemistry behaviors of SA508-4 low carbon alloy steel is very important. Further work should be concentrated on 

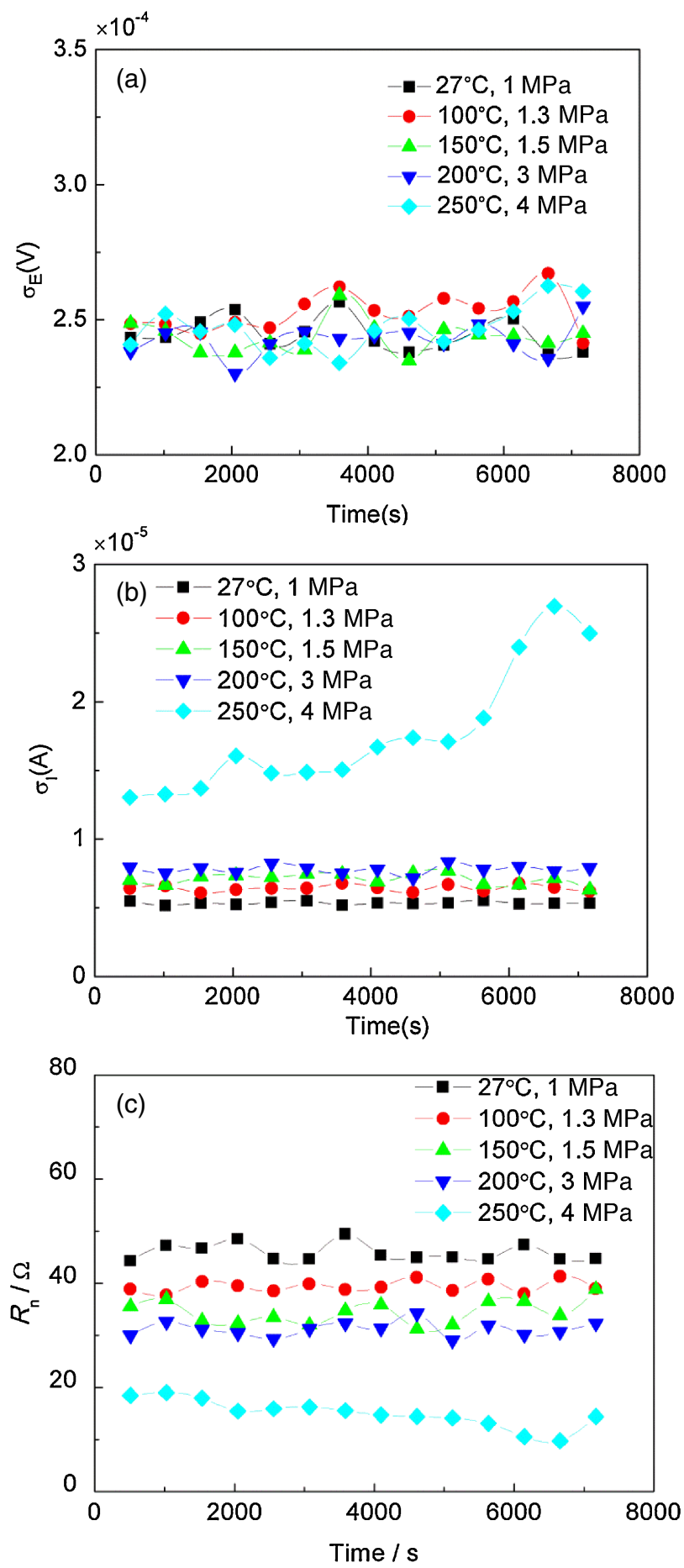

Figure 9. (Color online) The calculated standard deviation of potential (a), standard deviation of current (b), and noise resistance (c) at different temperature and pressure.

detecting the corrosion types, such as uniform corrosion, crack initiation and propagation in the stress corrosion cracking (SCC) process, intergranular corrosion, etc., by using the in-situ EN techniques.

\section{Acknowledgments}

The authors are happy to acknowledge financial support from National Key Basic Research Program of China (2011CB610505), Specialized Research Fund for the Doctoral Program of Higher Education (20120032110029).
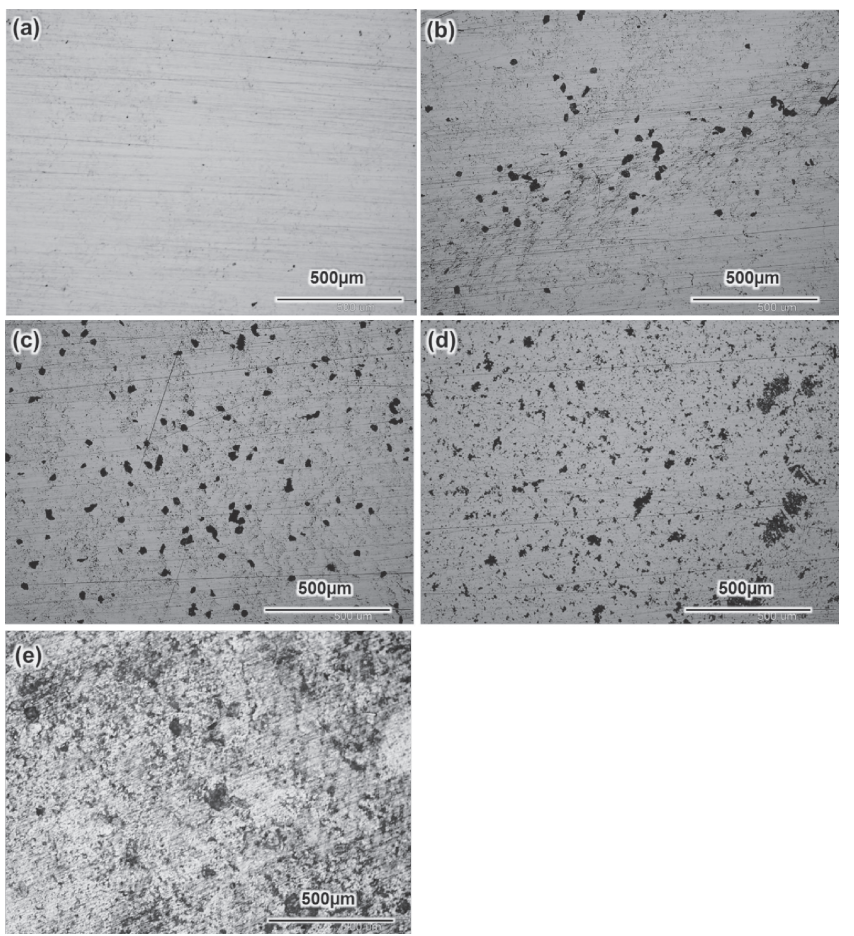

Figure 10. Corrosion morphology of SA508-4 Ni-Cr-Mo steel at different temperatures. (a) $27^{\circ} \mathrm{C}, 1.0 \mathrm{MPa}$; (b) $100^{\circ} \mathrm{C}, 1.3 \mathrm{MPa}$; (c) $150^{\circ} \mathrm{C}, 1.5 \mathrm{MPa}$; (d) $200^{\circ} \mathrm{C}, 3.0 \mathrm{MPa}$; (e) $250^{\circ} \mathrm{C}, 4.0 \mathrm{MPa}$.

\section{References}

1. J. M. Kim, C. H. D. Kwon, J. W. Joh, S. Song, M. Shin, S. J. Kim, S. H. Hong, B. N. Kim, and S. K. Lee, J. Korean Surg. Soc., 79, 267 (2010).

2. K.-H. Lee, S.-G. Park, M.-C. Kim, and B.-S. Lee, Mater. Sci. Eng., A, 534, 75 (2012).

3. Y.-S. Ahn, H.-D. Kim, T.-S. Byun, Y.-J. Oh, G.-M. Kim, and J.-H. Hong, Nucl. Eng. Des., 194, 161 (1999).

4. M. C. Carroll and L. J. Carroll, Mater. Sci. Eng., A, 556, 864 (2012).

5. W.-J. Yang, B.-S. Lee, Y.-J. Oh, M.-Y. Huh, and J.-H. Hong, Mater. Sci. Eng., A, 379, 17 (2004).

6. S. Amami, C. Lemaitre, A. Laksimi, and S. Benmedakhene, Corros. Sci., 52, 1705 (2010).

7. D. H. Xia, S. Z. Song, J. H. Wang, H. C. Bi, and Z. W. Han, Trans. Tianjin Univ., 18, 15 (2012).

8. D. H. Xia, S. Z. Song, J. H. Wang, H. C. Bi, and Z. W. Han, Acta Phys.-Chim. Sin., 28, 121 (2012).

9. D. H. Xia, J. H. Wang, Y. X. Jiang, N. Li, and C. Zhou, J. Tianjin Univ. (2013), accepted for publication.

10. A. M. Lafront, F. Safizadeh, E. Ghali, and G. Houlachi, Electrochim. Acta, 55, 2505 (2010).

11. D. H. Xia, J. B. Shi, W. Q. Gong, R. J. Zhou, Z. M. Gao, and J. H. Wang, Electrochemistry, 80, 907 (2012).

12. D. H. Xia, S. Z. Song, J. H. Wang, and H. C. Bi, CIESC J., 63, 1797 (2012).

13. H. D. Jung and A. Alfantazi, Electrochim. Acta, 51, 1806 (2006).

14. D. H. Xia, S. Z. Song, J. H. Wang, H. C. Bi, and Z. W. Han, Trans. Nonferrous Met. Soc. China, 22, 717 (2012).

15. S. Girija, U. Mudali, V. Raju, R. Dayal, H. Khatak, and B. Raj, Mater. Sci. Eng., A, 407, 188 (2005).

16. Y. Z. Lu, S. Z. Song, and L. H. Yin, Trans. Nonferrous Met. Soc. China, 15, 619 (2005).

17. R. Zhao, Z. Zhang, J. B. Shi, L. Tao, and S. Z. Song, J. Cent. South Univ. Technol, 17, 13 (2010).

18. G. Du, W. K. Wang, S. Z. Song, and S. J. Jin, Anti-Corros. Methods Mater, 57, 126 (2010).

19. G. Du, J. Li, W. K. Wang, C. Jiang, and S. Z. Song, Corros. Sci., 53, 2918 (2011).

20. D. H. Xia, S. Z. Song, J. H. Wang, J. B. Shi, H. C. Bi, and Z. M. Gao, Electrochem. Commun., 15, 88 (2012).

21. D. H. Xia, S. Z. Song, W. Q. Gong, Y. X. Jiang, Z. M. Gao, and J. H. Wang, J. Food Eng., 113, 11 (2012).

22. K.-H. Lee, M.-C. Kim, B.-S. Lee, and D.-M. Wee, Mater. Sci. Eng., A, 527, 3329 (2010).

23. B. S. Lee, M. C. Kim, J. H. Yoon, and J. H. Hong, Int. J. Pressure Vessels Piping, 87, 74 (2010). 